\section{Detección de la aterosclerosis carotídea y el riesgo de enfermedad cardiovascular}

La aterosclerosis carotídea, detectable por ultrasonografía de alta resolución, hoy en día se reconoce como un marcador de aterosclerosis generalizada y de la presencia de diferentes factores de riesgo cardiovascular. Aun antes de que se logre visualizar las placas de ateroma, la ultrasonografía carotídea permite medir el grosor de las capas íntima y media de la pared arterial, cuyo aumento es un fenómeno temprano que precede a la formación de placas de ateroma. Esto le confiere a la ultrasonografía la capacidad para revelar la frecuencia y progresión de la aterosclerosis en estudios seriados, la relación entre esta y algunos factores aterógenos, y cualquier modificación de los factores de riesgo por efecto de intervenciones farmacológicas.

Como parte de un proyecto encaminado a estudiar la aterosclerosis cerebral en México, un grupo de investigadores ha efectuado un estudio en residentes de la ciudad de México mayores de 55 años para establecer la frecuencia y extensión de las lesiones carotídeas ateroscleróticas, según el sexo y la edad; determinar la relación entre los factores de riesgo cardiovascular y la presencia y grado de la aterosclerosis carotídea; y establecer una comparación entre las personas menores y mayores de 65 años. De julio de 1993 a enero de 1996 se efectuó ultrasonografía carotídea en 145 individuos que residían en un centro multifamiliar. Se determinó una prevalencia de aterosclerosis carotídea de 64,8\%; un engrosamiento de las capas íntima y media en $44,1 \%$ (64) de los sujetos; y placas de ateroma en $56,5 \%$ (82) de los sujetos (junto con un engrosamiento de la íntima y media en 52). Solamente ocho personas $(5,5 \%)$ tuvieron una estenosis carotídea con efectos hemodinámicos de importancia. No hubo diferencias detectables en la prevalencia de aterosclerosis en relación con el sexo (hombres, $61,9 \%$; mujeres, $66,0 \%$ ). Los factores de riesgo cardiovascular asociados con la aterosclerosis fueron la edad $(P<0,0001)$, hipertensión arterial sistémica $(P<0,001)$, hipertensión sistólica aislada $(P=0,01)$, hipercolesterolemia $(P=0,04)$ y diabetes mellitus $(P=0,06)$. La prevalencia de aterosclerosis carotídea mostró un aumento paralelo al del número de factores de riesgo cardiovascular.

La prevalencia de aterosclerosis detectada en este estudio fue elevada y similar a la observada en otros países occidentales. Pero a diferencia de otros estudios que han identificado el tabaquismo y el consumo de alcohol como factores independientes en el desarrollo de aterosclerosis carotídea, el estudio aquí descrito no arrojó ninguna asociación significativa. El sexo tampoco fue un factor predictor, lo cual concuerda con lo revelado por estudios en otras poblaciones al efecto de que la diferencia en la prevalencia de placas de ateroma según el sexo es más destacada en personas menores de 60 años y disminuye conforme avanza la edad. Por otra parte, la poca frecuencia de lesiones carotídeas estenosantes coincide con la hallada en otras poblaciones. Si se considera que el índice de placas aumenta con la edad, los resultados aquí presentados concuerdan con los de otros estudios que señalan que la aterosclerosis en personas de edad avanzada se suele extender a lo largo del vaso con distribución multisegmentaria, y no hacia el lumen de forma oclusiva. (Cantú-Brito C, Rodríguez-Saldaña J, Reynoso-Marenco MT, Marmolejo-Henderson R, Barinagarrementeria-Aldatz F. Factores de riesgo cardiovascular y aterosclerosis carotídea detectada por ultrasonografía. Salud Publica Mex 1999;41(6): 452-459.)

\section{Los resultados del embarazo: ¿Qué nos dicen las concentraciones séricas de gonadotropina coriónica?}

La gonadotropina coriónica en el suero materno se mide con objeto de detectar anomalías cromosómicas en el feto y es posible que su medición también se pueda usar para predecir el riesgo de complicaciones o de un resultado gestacional adverso. Con el fin de dilucidar esto último, se llevó a cabo una revisión de 28743 fichas clínicas pertenecientes a mujeres embarazadas cuyas concentraciones de gonadotropina coriónica se midieron durante el segundo trimestre del embarazo, extrayéndose simultáneamente información sobre sus complicaciones y resultados. Se excluyó de la muestra a las mujeres con otros factores de riesgo de sufrir complicaciones o de tener un resultado gestacional adverso.

Se detectó una asociación entre altas concentraciones de gonadotropina coriónica y mayores porcentajes de niños mortinatos (razón de posibilidades [RP] por cada aumento de la gonadotropina 
coriónica equivalente a un múltiplo de la mediana: 1,4; IC95\%: 1,1 a 1,9). No se observó ninguna asociación entre un aumento de las concentraciones séricas de gonadotropina coriónica y el riesgo de diabetes gestacional, ruptura prematura de membranas o retraso del crecimiento intrauterino o pequeñez para la edad gestacional (RP: 1,1; IC95\%: 0,9 a 1,2). Se observó una asociación entre un aumento de las concentraciones de gonadotropina coriónica y el riesgo de anomalías placentarias (RP: 1,5; IC95\%: 1,3 a 1,7), hipertensión gestacional (RP: 1,4; IC95\%: 1,3 a 1,5), y parto prematuro sin hipertensión gestacional (RP: 1,1; IC95\%: 1,0 a 1,2). El pertenecer a determinada categoría racial o étnica (negro, filipino o procedente de las islas del Pacífico, raza o grupo étnico desconocido, y "otra", categoría que abarca a las personas de origen mediterráneo oriental y a las poblaciones oriundas de los Estados Unidos) fue un mejor factor predictivo del riesgo de un resultado adverso que los valores de gonadotropina coriónica.

Se concluye a partir de estos resultados que las concentraciones de gonadotropina coriónica en el suero materno tienen escaso valor a la hora de pronosticar el riesgo de complicaciones y el resultado del embarazo. (Walton DL, Norem CT, Schoen EJ, Ray GT, Colby CJ. Second-trimester serum chorionic gonadotropin concentrations and complications and outcome of pregnancy. $N$ Engl J Med 1999;341(27): 2033-2038).

\section{Se detecta relación entre la concentración de la grasa corporal y la depresión en el embarazo}

Es un hecho confirmado que mientras más joven es una mujer embarazada, más alto es el riesgo que corre de tener problemas de salud durante el embarazo o de dar a luz a un niño de bajo peso. Desde el punto de vista nutricional, el aumento de peso durante el embarazo es distinto en adolescentes y mujeres adultas. Las mujeres más jovencitas necesitan tener un aumento de peso corporal mayor si el neonato ha de nacer con un peso normal. Algunos investigadores también han observado que las adolescentes suelen tener neonatos más pequeños que las mujeres adultas, aunque aumenten el mismo número de libras durante la gestación, lo cual implica que los hijos de madres adolescentes son más propensos a sufrir muerte fetal o a morir en el período neonatal.

Desde el punto de vista psicológico, el embarazo durante la adolescencia se asocia con trastornos emocionales, principalmente ciertos estados depresivos y de ansiedad, y las jóvenes que muestran estos síntomas tienden a su vez a depositar un exceso de grasa corporal. No obstante, ningún estudio ha demostrado que haya una asociación entre la de- presión y el aumento de peso durante el embarazo. Con el fin de determinar si dicha asociación existe, un grupo de investigadores de un hospital escuela en México, D.F., llevó a cabo un estudio de casos y testigos en 85 embarazadas (45 adolescentes y 40 adultas) que asistían a una clase de cuidados prenatales. Durante los dos últimos trimestres de la gestación, se aplicó una prueba propuesta por Zung para determinar quiénes tenían síntomas de depresión. A todas las mujeres se les hicieron mediciones de peso y del grosor del pliegue cutáneo (del tríceps, bíceps, pliegue suprailíaco, pliegue subescapular y muslo) a partir de la vigésima semana de la gestación y hasta la cuarta semana después del alumbramiento, con seguimientos mensuales posteriores.

Los resultados del estudio revelaron que en la vigésimo octava semana gestacional $40 \%$ de las adolescentes embarazadas tenían puntajes que superaban el punto de corte en la prueba detectora de estados depresivos, mientras que en las adultas esta proporción correspondió a 15\%. En las adolescentes, la presencia o ausencia de síntomas de depresión mostró relación con su grado de autoestima. El porcentaje de peso corporal en mujeres adultas se mostró constante, mientras que en las adolescentes se halló una tendencia hacia una mayor acumulación de grasa corporal. Los estados depresivos, y particularmente la falta de autoestima y el aumento de peso durante el embarazo, fueron las variables con mayor valor predictivo en relación con el patrón de obesidad durante el embarazo, mientras que en los adultos no se halló ninguna variable que sirviera para pronosticar la acumulación de grasa corporal. En resumen, la depresión coloca a las embarazadas adolescentes en riesgo de sufrir un aumento excesivo de peso durante el período gestacional. (Casanueva E, Labastida J, Sanz C, MoralesCarmona F. Depression and body fat deposition in Mexican pregnant adolescents. Arch Med Res 2000;31:48-52.)

\section{Efecto del tratamiento de reposición hormonal en los resultados de la mamografía}

Se han efectuado estudios controlados aleatorizados que han mostrado una reducción de la mortalidad por cáncer de mama gracias a la mamografía. No obstante, muchos programas de tamizaje a base de esta técnica radiológica pueden servir para reducir la mortalidad únicamente si tienen alta sensibilidad y pueden detectar lesiones cancerosas muy pequeñas. La precisión de los resultados obtenidos con la mamografía varía según la edad de la mujer, la densidad del mamograma y los antecedentes familiares de cáncer de mama. Otros estudios han demostrado que la administración de tera- 
pia de reposición hormonal (TRH) podría asociarse con una reducción de la especificidad y sensibilidad de la mamografía, aunque también ha habido estudios en los cuales estas asociaciones no han sido detactadas. Debido a la creciente popularidad de la $\mathrm{TRH}$, es importante determinar si ejerce, de hecho, alguna influencia sobre los resultados de la mamografía. Hay quienes han postulado que la frecuencia más alta de cáncer de mama que se observa en el Reino Unido y en Australia es consecuencia de la reducción de la sensibilidad de la mamografía debido a la administración de la TRH.

En Victoria, Australia, se llevó a cabo un estudio para determinar la sensibilidad y especificidad de la mamografía y su capacidad para detectar lesiones pequeñas en mujeres australianas con y sin TRH. La muestra se compuso de 103770 mujeres mayores de 40 años que habían acudido a un programa de tamizaje por primera vez en 1994 y que carecían de antecedentes personales de cáncer de mama, masas en el seno o secreción sanguinolenta o acuosa por el pezón en el momento del examen. Se aplicó un modelo de regresión logística incondicional a fin de hacer ajustes según edad, antecedentes familiares y presencia o ausencia de síntomas.

Se encontró que la sensibilidad de la mamografía, efectuada a intervalos de 2 años, fue 12,5\% menor en mujeres de todas las edades que recibían TRH. La sensibilidad para el primer año solamente fue de 91,4\% (IC95\%: 89 a 94) en mujeres sin TRH y de 83,7\% (IC95\%: 78 a 90) en mujeres que sí recibían TRH. Se observó también una pequeña reducción $(0,6 \%)$ de la especificidad, independientemente de la edad de la mujer.

Después de hacer ajustes por edad, la mamografía mostró menos sensibilidad $(P<0,001)$ en las usuarias de TRH que tenían de 50 a 69 años en el momento del tamizaje (64,3\% [IC95\%: 57 a 72]) que en las mujeres de la misma edad que no recibían TRH (79,8\% [IC95\%: 76 a 84]). No hubo diferencias significativas de sensibilidad en mujeres de 40 a 49 años en virtud del uso de HRT.

La regresión logística reveló que las usuarias de TRH en quienes se diagnosticó cáncer de mama durante el intervalo de 2 años entre mamografías mostraron una mayor tendencia a tener resultados radiológicos negativos falsos. Este efecto se atenuó ligeramente cuando se hicieron los ajustes según edad, ausencia o presencia de síntomas y antecedentes familiares (razón de posibilidades: 1,60; IC95\%: 1,04 a 2,$21 ; P=0,01$ ). La sensibilidad ajustada fue de $74,7 \%$ en usuarias y de $64,8 \%$ en no usuarias de TRH. El riesgo de un tamizaje negativo falso en usuarias de TRH siendo de un año el intervalo entre mamografías fue similar al observado en un intervalo de 2 años.
Las usuarias de TRH en quienes no se diagnosticó cáncer de mama durante el intervalo entre mamografías mostraron un riesgo ligeramente mayor que las no usuarias de tener un resultado radiológico positivo falso. El ajuste por edad, ausencia o presencia de síntomas y antecedentes familiares no alteró la especificidad de manera significativa.

Con este estudio se ha logrado demostrar que la TRH se acompaña de una menor sensibilidad en los resultados de la mamografía. En países donde existen programas de tamizaje a base de mamografía a escala poblacional, esta reducción de la sensibilidad podría menoscabar su capacidad para reducir la mortalidad por cáncer de mama. (Kavanagh AM, Mitchell H, Giles GG. Hormone replacement therapy and accuracy of mammographic screening. Lancet 2000;355:270-274.)

\section{Se sabe por qué algunas personas infectadas por el VIH no progresan al sida}

Por motivos que se desconocen, una pequeña fracción de los individuos infectados por el virus de la inmunodeficiencia humana (VIH) no presentan síntomas de sida por un período de tiempo mucho mayor que el esperado. Según un informe recién emitido por investigadores del Instituto Nacional de Alergias y Enfermedades Infecciosas de los Estados Unidos de América, un subgrupo muy pequeño de estos individuos bien podría salvarse de llegar a tener sida. Los datos aportados por estos investigadores, que se publicaron en marzo de este año, proveen información novedosa y de posible utilidad para la elaboración de una vacuna o de otros tratamientos contra el VIH.

Aparentemente hay un rasgo común en el sistema inmunitario de las personas infectadas por VIH que no contraen el sida. Específicamente se han encontrado diferencias, mediante la investigación de 13 personas seropositivas a VIH durante más de 15 años que además fueron escogidas por tener recuentos normales de linfocitos CD4+ y concentraciones sanguíneas de VIH extremadamente bajas, en algunos de los genes que codifican las proteínas de los antígenos leucocitarios del ser humano (human leukocyte antigens, HLA). En el caso de las infecciones por VIH y de otras infecciones víricas, dichas proteínas se adhieren a las partículas víricas dentro de las células infectadas y conducen a estas partículas atrapadas hacia la superficie celular, donde las presentan, por así decirlo, a los linfocitos $\mathrm{T}$ que proceden a destruir a las células infectadas. Prácticamente todas las células del organismo tienen proteínas de HLA, aunque estas son distintas en cada individuo. Debido a que un tipo determinado de proteína 
puede adherirse mejor que otro a los fragmentos de un microorganismo específico, las personas con ciertos genes HLA tienen más resistencia a algunas infecciones, en este caso a la infección por VIH.

En el estudio citado, los investigadores descubrieron que 11 de los 13 (85\%) sujetos tenían una variante genética denominada HLA B*5701, mientras que solamente 19 de 200 (9,5\%) individuos que desarrollaron síntomas de sida tenían esta variante. Además, cuando los investigadores examinaron las células $\mathrm{T}$ de los casos con resistencia al sida, hallaron que muchas de ellas reconocieron la variante genética HLA B*5701 cuando se encontraba adherida a fragmentos proteínicos específicos. Esto sugiere que el motivo por el cual algunas personas tienen más resistencia que otras al sida radica en su sistema inmunitario, y no en que estén infectadas por una forma atenuada del VIH.

Es primera vez que se observa una asociación rotunda entre la resistencia al sida y factores genéticos relacionados con el sistema inmunitario. En el futuro habrá que investigar de qué manera la variante genética HLA B*5701 confiere protección y por qué la proteína no parece proteger al pequeño porcentaje de personas que tienen esta variante pero que sí desarrollan síntomas de sida. (National Institutes of Health. NIAID researchers discover why some HIV-infected people don't develop AIDS. Comunicado de prensa, 15 de marzo de 2000.)

\section{El tabaquismo materno y su efecto en embarazos simples y gemelares}

Se sabe a ciencia cierta que el tabaquismo materno tiene efectos adversos en el producto de un embarazo simple: retraso del crecimiento intrauterino (y como consecuencia bajo peso al nacer), síndrome de la muerte súbita neonatal, desprendimiento de la placenta, parto prematuro, y demás. También está prácticamente establecido que estos trastornos se producen por mediación del monóxido de carbono y de la nicotina, que reducen, respectivamente, la transferencia de oxígeno a la placenta y la llegada de sangre a ese órgano por las arterias uterinas. No obstante, aún se desconocen con exactitud los efectos del tabaquismo materno en los embarazos múltiples, que plantean una mayor demanda de oxígeno placentario y que, de por sí, acarrean un mayor riesgo de parto prematuro, bajo peso al nacer y muerte neonatal. En estos embarazos es posible que el tabaquismo materno sea aun más peligroso que en el caso de un embarazo simple, y algunos estudios en gestaciones gemelares han confirmado la sospecha. Pocos de ellos, sin embargo, han tenido carácter poblacional, situa- ción que ha llevado a un grupo de investigadores estadounidenses a realizar una investigación en embarazos simples y gemelares identificados mediante datos recogidos por el National Center for Health Statistics sobre la mortalidad perinatal en 1995.

Los investigadores crearon un algoritmo para identificar a los pares de gemelos y posteriormente efectuaron un análisis de regresión logística con resultados aleatorios para estimar la asociación entre el tabaquismo materno y diversos trastornos en una muestra aleatoria de productos de embarazos simples y en todos los productos de embarazos gemelares para los cuales se tenía información sobre los hábitos tabáquicos de la madre.

El algoritmo vinculó a 91\% de los pares de gemelos. El tabaquismo materno mostró una asociación con un riesgo significativamente mayor de bajo peso al nacer, peso muy bajo al nacer y edad gestacional menor de 33 semanas al nacer en niños gemelos y no gemelos, así como un mayor riesgo de edad gestacional menor de 38 semanas al nacer, mortalidad durante el primer año de vida y desprendimiento de la placenta en el caso de neonatos no gemelos. Entre las madres que fumaban, el efecto adverso en el riesgo de bajo peso al nacer, peso muy bajo al nacer y parto extremadamente prematuro fue significativamente mayor en el caso de mujeres con embarazos gemelares.

Se concluye a partir de estos resultados que algunos de los efectos adversos que ejerce el tabaquismo en el peso y la edad gestacional al nacer se acentúan en el caso de embarazos gemelares. (Pollack H, Lantz PM, Frohna JG. Maternal smoking and adverse birth outcomes among singletons and twins. Am J Public Health 2000;90(3):395-400.)

\section{Descubrimiento sobre los cambios víricos que llevan a la hepatitis $C$ crónica}

Científicos de los Institutos Nacionales de Salud y de otras instituciones han descubierto una pista que explica, al menos de manera preliminar, por qué muchos pacientes nunca se recuperan de la infección con el virus de la hepatitis C (VHC). Sus resultados apuntan a determinados cambios en la estructura de las proteínas de la superficie vírica que impiden que el virus sea detectado por el sistema inmunitario. Según el estudio, el resultado ulterior de la infección por el VHC queda definido desde la fase aguda de la enfermedad.

La hepatitis C cobra muchas vidas en el mundo entero. Solamente en los Estados Unidos, casi 4 millones de individuos han sido infectados por el virus de la hepatitis C. De los que contraen la 
enfermedad $85 \%$ quedan con infección crónica y tienen latente en el organismo un virus que sigue replicándose durante el resto de la vida del paciente. El VHC es una de las principales causas de enfermedad hepática y da origen a una tercera parte de todos los casos de cirrosis y de hepatomas malignos, a la mitad de todos los transplantes de hígado y a 8000 a 10000 defunciones anuales en los Estados Unidos.

De 12 pacientes que participaron en el estudio, algunos habían tenido hepatitis $C$ durante más de 20 años y fueron observados desde el inicio de la infección para determinar si el virus sufría cambios a lo largo del tiempo. Tres de los pacientes estudiados tenían infecciones agudas por el VHC, tres tenían hepatitis fulminante (forma rara y peligrosa de la enfermedad) y seis tenían hepatitis crónica. El grupo de investigadores examinó a cada persona, fijándose en particular en cualquier cambio en los genes que codifican las proteínas especiales que revisten la superficie vírica. También estudiaron los cambios que habían ocurrido antes o después de la respuesta del sistema inmunitario a la infección.

En algunos pacientes el virus permaneció relativamente estable inmediatamente después de la respuesta inmunitaria inicial y estos pacientes lograron eliminar el VHC del organismo en el transcurso de varias semanas. En la mayoría, sin em- bargo, empezaron a observarse variantes genéticas a raíz del ataque inicial contra el sistema inmunitario. Esta evolución rápida del virus con el tiempo dio origen a una infección crónica. En tales casos el virus, en efecto, es más "inteligente" que las defensas del organismo y empieza a alterar las proteínas de su superficie tan pronto comienzan a montar su respuesta los primeros anticuerpos. El virus "se disfraza" y pasa desapercibido en lo sucesivo.

Otros virus que atacan al ser humano adoptan "disfraces" similares, entre ellos los de la inmunodeficiencia adquirida y la influenza, pero este estudio es el primero en detectar una correlación entre estos mecanismos de adaptación y la evolución de la hepatitis C. Los investigadores también lograron identificar la zona en las proteínas de la superficie vírica donde ocurren casi todos los cambios proteínicos. De ahora en adelante su atención será dirigida hacia el tipo de mutaciones que ayudan al VHC a evadir el sistema inmunitario y el tipo de anticuerpos que se producen durante la respuesta inmunitaria más temprana. Se espera que una vez que se entiendan mejor estos aspectos de la evolución de la infección por el VHC, se pueda elaborar técnicas nuevas para tratar y prevenir la hepatitis $C$. (National Institutes of Health. NIH researchers zero in on viral changes that lead to chronic hepatitis $\mathrm{C}$. Comunicado de prensa, 13 de abril de 2000.) 